\title{
Pengaruh Motivasi Terhadap Prestasi Pada Atlet Klub Bulutangkis Indocafe Medan Tahun 2020
}

\author{
The Effect of Motivation on Achievement in Indocafe Medan Badminton Club Athletes \\ in 2020
}

\author{
Shah Reza ${ }^{1}$, Nono Hardinoto ${ }^{2}$ \\ ${ }^{1,2}$ Fakultas Ilmu Keolahragaan, Universitas Negeri Medan \\ Email: shanksakagami005@gmail.com
}

\begin{abstract}
ABSTRAK
Penelitian ini bertujuan untuk mengetahui bagaimana pengaruh dari motivasi latihan terhadap prestasi bulutangkis. Populasi dalam penelitian ini adalah seluruh atlet PB Indocafe Medan, tahun 2020 yang berjumlah 52 orang. Jumlah sampel 21 orang diperoleh dengan teknik purposif sampling dimana sampel adalah atlet yang mengikuti kejuraan Daihatsu Astec Open Tahun 2020 di Medan Sumatera Utara. Instrumen yang digunakan dalam penelitian ini adalah instrumen motivasi latihan dan prestasi diukur dari pencapaian setiap atlet pada pertandingan Daihatsu Astec Open Tahun 2020 di Medan Sumatera Utara. Hasil analisis statistik menunjukkan koefisien korelasi sebesar 0,007 yaitu mempunyai hubungan yang sangat rendah. Koefisien determinasi sebesar $0,07 \%$ menjelaskan bahwa motivasi latihan memberikan pengaruh sebesar $0,07 \%$ terhadap prestasi bulutangkis, sedangkan $99,3 \%$ dipengaruhi oleh variabel yang lain. Dari hasil output diketahui bahwa nilai $\mathrm{t}=(-0,361)$ dengan nilai $\alpha=0,05 \mathrm{dan} \mathrm{dk}=\mathrm{n}-1=19$ diketahui $\mathrm{t}(19,0,95)=1,73$. Dalam kriteria pengujian hipotesis satu arah dinyatakan bahwa $t_{\text {Hitung }}<t_{\text {Tabel }}(-$ $0,361<1,73)$. Maka dapat disimpulkan tidak terdapat pengaruh yang signifikan dari motivasi latihan terhadap prestasi bulutangkis. Adapun persamaan regresinya adalah: $Y=4,156+(-0,024) X$. Untuk menguji apakah persamaan tersebut berarti atau tidak digunakan analisis dengan nilai $\mathrm{F}$ dimana $F_{\text {hitung }}=0,130$ sedangkan $F_{\text {tabel }(1,19)}$ sebesar 4,38. Karena $F_{\text {hitung }}<F_{\text {tabel }}(0,130<4,38)$ maka dapat disimpulkan bahwa persamaan regresi antara motivasi latihan dengan prestasi bulutangkis adalah tidakberarti.
\end{abstract}

\section{Kata Kunci: Motivasi, Prestasi, Bulutangkis.}

\begin{abstract}
This study aims to determine how the influence of training motivation on badminton achievement. The population in this study were all PB Indocafe Medan athletes, in 2020, totaling 52 people. The number of samples of 21 people was obtained by purposive sampling technique where the sample was athletes who participated in the 2020 Daihatsu Astec Open championship in Medan, North Sumatra. The instrument used in this study was an instrument of training motivation and achievement measured from the achievements of each athlete at the 2020 Daihatsu Astec Open competition in Medan, North Sumatra. The result of statistical analysis shows that the correlation coefficient is 0.007 , which is a very low relationship. The determination coefficient of $0.07 \%$ explains that training motivation has an effect of $0.07 \%$ on badminton achievement, while $99.3 \%$ is influenced by other variables. From the output it is known that the value of $\mathrm{t}=(-0.361)$ with a value of $\alpha=0.05$ and $\mathrm{dk}=\mathrm{n}-1=19$, it is known that $\mathrm{t}(19,0.95)=1.73$. In the one-way hypothesis testing criteria, it is stated that tcount $<$ ttable $(-$
\end{abstract}


$0.361<1.73)$. So it can be concluded that there is no significant effect of training motivation on badminton achievement. The regression equation is: $\mathrm{Y}=4.156+(-0.024) \mathrm{X}$. To test whether the equation is meaningful or not, an analysis with $\mathrm{F}$ value is used where Fcount $=0.130$ while Ftable (1.19) is 4.38. Because Fcount <Ftable $(0.130<4.38)$, it can be concluded that the regression equation between training motivation and badminton achievement is meaningless.

\section{Keywords: Influence of Motivation on Achievement, Badminton.}

\section{PENDAHULUAN}

Indonesia menjadi salah satu negara yang memiliki pemain-pemain bulu tangkis di level dunia. Hal tersebut karena raihan prestasi pada pertandingan yang dapat dimenangkan pada level tertinggi (Arifin, A. Z., Januarto, O. B., \& Tomi, A., 2020). Atlet-atlet Indonesia sangat diperhitungkan oleh pemain-pemain dari negara lain.

Adapun beberapa nama atlet Indonesia yang telah menjadi legenda di dunia bulutangkis adalah (1) Rudi Hartono 19701982 adalah juara satu All England sebanyak 7 kali. (2) Liem Swie King adalah peraih 3 kali juara All England, 4 kali juara Sea Games dan 1 Kali Juara Asian Games serta 3 kali membawa Indonesia Juara Thomas Cup. (3) Christian Hadinata peraih 2 kali juara Asian Games, 4 kali All England dan 3 kali Juara Dunia selain itu pada saat ini menjadi pelatih ganda yang disegani. (4) Susi Susanti adalah peraih juara Sudirman Cup, 2 kali mengantarkan Indonesia menjuarai Uber Cup, 6 kali Juara Dunia, dan peraih medali emas olimpiade 1992. (5)
Rexy Mainaky - Ricky Soebagja berhasil menjadi juara lebih dari 30 kali pada pertandingan bergengsi. (6) Taufik Hidayat berhasil menjadi Juara Dunia, meraih medali emas olimpiade 2004 di Athena, 3 kali Juara Asia, 3 kali juara Asian Games serta 2 kali mengantarkan Indonesia meraih juara Thomas Cup.

Untuk menjaga tradisi juara dari para pendahulunya regenerasi pemain terus dilakukan oleh PBSI (Persatuan Bulu Tangkis Seluruh Indonesia) baik dengan memberikan beasiswayang bekerja sama dengan beberapa perusahaan nasional sehingga memberikan minat dan motivasi besar pada pemain-pemain junior untuk berlatih lebih keras dan memilih menjadi atlet bulutangkis. Adapun pembinaan yang dilakukan oleh PBSI dapat dikatakan cukup baik yang mana banyak atlet Indonesia yang dapat mengikuti langkah seniornya di levelinternasional antara lain Marcus Fernaldi Gideon Dan Kevin Sanjaya Sukamuljo, Tontowi Ahmad, Anthony Ginting, Jonatan Christie dan masih banyak 
lagi.

Untuk menjadi juara tentu dibutuhkan motivasi atau dorongan untuk berlatih dan meningkatkan kemampuan diri. Baik motivasi ekstrinsik maupun motivasi instrinsik harus selalu diberikan pada atlet baik oleh pelatih, orang tua maupun orangorang di sekitarnya. Karena dengan motivasi yang tinggilah atlet akan mau berlatih setiap hari lebih dari 2 jam, menempah kondisi fisik agar mampu bertahan dalam persaingan yang semakin ketat, melatih kemampuan teknik dan taktik bermain serta melatih kemampuan psikis agar kuat menghadapi situasi latihan dan juga situasipertandingan.

Motivasi mencerminkan kemampuan atlet untuk meningkatkan kemampuan diri dan mengarahkan energi kearah yang jelas atau positif. Motivasi juga akan membentuk rasa percaya diri untuk dapat tampil secara konsisten sehingga dapat meraih prestasi terbaik (Juariyah, L., \& Adi, S. S., 2017).

Motivasi menjadi kebutuhan bagi setiap atlet baik untuk berlatih dan juga pada saat bertanding dengan demikian perlu kiranya atlet tetap diberikan motivasi agar dapat mempertahankan keinginan dan kemauannya untuk menjadi yang terbaik dalam permainan bulutangkis.

Salah satu klub di PBSI Sumatera Utara adalah PB Indocafe yang mana latihan dipusatkan di Lapangan PBSI Jalan Gedung PBSI, Kenangan Baru, Kec. Percut Sei Tuan, Kabupaten Deli Serdang, Sumatera Utara. Adapun jumlah atlet yang latihan di Klub ini adalah lebih dari 50 orang yang mana latihan dilakukan setiap hari mulai pukul 15.00-18.00.

Pembinaan pada PB Indocafe telah dilakukan sejak tahun 2002 dan prestasi atlet yang diraih masih pada level daerah Sumatera Utara sedangkan untuk bersaing di level nasional masih sangat sulit. Banyak hal yang mengakibatkan prestasi atlet PB Indocafe Medan belum bisa bersaing di level nasional bahkan di level internasional antara lain kemampuan psikis atau mental.

\section{METODE PENELITIAN}

Penelitian ini dilaksanakan di lokasi latihan klub PB Indocafe yaitu Jl. Gedung PBSI, Kenangan Baru, Kec. Percut Sei Tuan, Kabupaten Deli Serdang, Sumatera Utara. Pelaksanaan penelitian dilaksanakan mulai tanggal 3 Agustus 2020, yang mana pelaksanaan penelitian dilakukan dengan memberikan angket isian kepada atlet PB Indocafe melalui Google Form dan juga berkoordinasi dengan pelatih mengenai hasil pencapaian dari setiap atlet saat mengikuti pertandingan Daihatsu Astec Open Tahun 2020 di Sumatera Utara. 
Populasi merupakan semua individu yang dilibatkan dalam penelitian dimana mempunyai karakteristik yang sama (Purnamaningsih, I. R., 2019). Adapun yang menjadi populasi penelitian ini seluruh atlet bulutangkis PB Indocafe yang terdaftar sebagai anggota aktif pada tahun 2020. Jumlah populasi tersebut adalah 52 orang atlet.

Sampel adalah sebagian atau wakil populasi yang diteliti. Dalam penelitian ini sample diambil dari populasi dengan teknik purposive random sampling. Menurut Sugiyono (2007: 85), purposive sampling adalah teknik penentuan sampel dengan pertimbangan tertentu. Kriteria dalam penentuan purposive sampel adalah atlet yang mengikuti pertandingan bulutangkis di tingkat Sumatera Utara pada tahun 2020 yang berjumlah 21 orang.

Metode penelitian yang digunakan dalam penelitian ini adalah metode kuantitatif deskriptif yang mana penelitian dilakukan untuk melihat gambaran dari motivasi pada atlet PB Indocafe pada saat mengikuti pertandingan. Penelitian ini berupa kumpulan data yang nantinya dituangkan dalam bentuk laporan dan uraian untuk mengetahui motivasi pada atlet PB Indocafe Medan pada tahun 2020.
Ditinjau dari sifatnya, metode yang digunakan dalam penelitian ini menggunakan metode penelitian ex-post facto, yaitu penelitian yang dilakukan untuk meneliti suatu peristiwa yang sudah terjadi dan kemudian merunut ke belakang untuk mengetahui faktor-faktor yang dapat menyebabkan timbulnya kejadian tersebut (Sepriadi, S., 2017).

Instrumen penelitian yang digunakan untuk mengumpulkan data dalam dalam penelitian ini adalah dengan melakukan pengukuran terhadap variabel yang terdapat dalam penelitian ini. Adapun instrumen yang digunakan adalah motivasi latihan untuk mengukur motivasi latihan atlet PB Indocafe dan instrumen prestasi untuk mengukur prestasi atlet tersebut adapun penjelasan adalah angket atau kuesioner.

Peneliti menggunakan aplikasi google form untuk memberikan kemudahan kepada sampel mengisi angket. Setelah data terkumpul, maka data yang diperoleh harus diolah terlebih dahulu menggunakan rumusrumus statistika sebelumnya akhirnya di analisis. Pengujian persyaratan analisis dengan menggunakan aplikasi SPSS dimana uji syarat analisis dalam regerasi adalah uji normalitas dan uji linieritas. 
Tabel 1. Kisi-Kisi Angket Motivasi

Variabel Faktor Indikator

1. Menguasai semua teknik dan taktik bermain

Motivasi Intrinsik Latihan

Atlet

Bulutang

kis

PB

Indocaf

e

Medan

bulutangkis

2. Mau belajar dan berlatih untuk meningkatkan kemampuan teknik bulutangkis

3. Mengembangka $n$ sikap ingin berhasil

4. Ingin diterima oleh orang lain

5. Menyenangi olahraga bulutangkis

1. Pujian/

Penghargaan

2. Teman

Ekstrinsik

4. Fasilitas Latihan

5. Lingkungan

tempat tinggal

Tabel 2. Penilaian Prestasi Bulutangkis

\begin{tabular}{cc}
\hline $\begin{array}{c}\text { Babak Pertandingan Yang } \\
\text { Diikuti }\end{array}$ & $\begin{array}{c}\text { Penilaian } \\
\text { Prestasi }\end{array}$ \\
\hline Winner & 9 \\
\hline Finalis & 8 \\
\hline Semi Finalis & 7 \\
\hline Babak 8 Besar / Quarter Final & 6 \\
\hline Babak 16 Besar / Round 3 & 5 \\
\hline Babak 32 / Round 2 & 4 \\
\hline Babak 64 / Round 1 & 3 \\
\hline Babak Final Kulaifikasi \\
Round 2 & 2 \\
\hline Babak Final Kulaifikasi \\
Round 1
\end{tabular}

\section{HASIL DAN PEMBAHASAN}

Atlet PB Indocafe mempunyai motivasi latihan rata-rata sebesar $84 \%$ yang terdiri dari $92 \%$ adalah motivasi intrinsik dan $74 \%$ adalah motivasi ekstrinsik. Penyebaran data tersebut dapat dilihat pada grafik motivasi latihan $(\mathrm{X})$ dibawah ini.

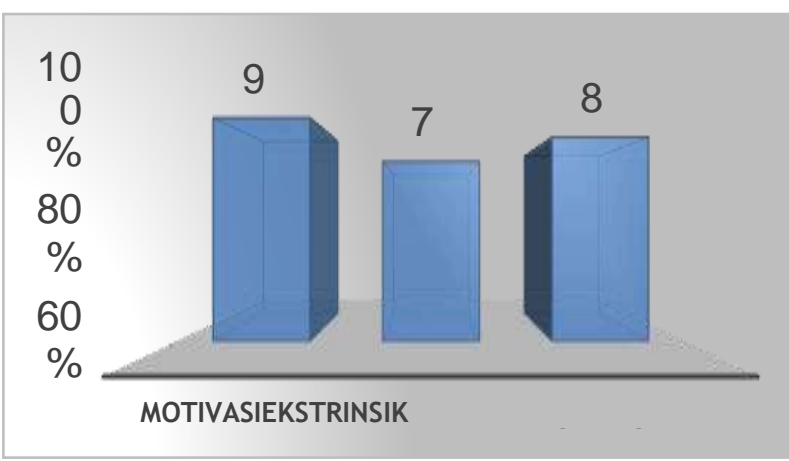

\section{Gambar 1. Persentase Motivasi Latihan Atlet PB Indocafe}

Deskripsi data pencapaian atlet PB Indocafe pada pertandingan Daihatsu Astec Open Tahun 2020 di Sumatera Utara pada penelitian ini bertujuan untuk menggambarkan data penelitian dari variabel tersebut dengan lebih rinci melalui tabel sehingga lebih mudah untuk memahami penyebaran dari data yang diperoleh melalui tes danpengukuran.

Terdapat 4 atlet yang dapat mencapai perempat final atau babak 8 besar yaitu 1 pasangan ganda dan 2 pemain tunggal. Untuk pencapaian di babak semi final, final dan winner tidak ada sama sekali. Hal ini dikarenakan banyaknya pemain yang mengikuti pertandingan ini dari berbagai 
daerah seluruh Indonesia sehingga persaingannya sangat ketat. Oleh sebab ketatnya persaingan tersebut terdapat 2 orang atlet PB Indocafe yang kalah pada babak penyisihan atau kualifikasi dimana kedua pemain tersebut kalah di partai tunggal yaitu round 2 kualifikasi dengan demikian mereka bahkan tidak bisa mengikuti pertandingan elimination.

Dalam penelitian ini uji normalitas yang digunakan adalah uji kolmogorov smirnov dengan perhitungan analisis menggunakan aplikasi SPSS. Adapun dasar pengambilan keputusan pada uji kolmogorov smirnov; Jika nilai sig. (signifikansi) > dari 0.05 maka data berdistribusi normal, sedangkan jika nilai sig. (signifikansi) $<$ dari 0.05 maka data tidak berdistribusi normal. Hasil uji normalitas kolmogorov smirnov diperoleh nilai test statistic 0.138 dan asymp.sig 0.200, nilai tersebut lebih besar dari nilai $\alpha$ (0.05). Sehingga dapat disimpulkan bahwa sebaran data adalah berdistribusi normal.

Dari hasil output SPSS pada ANOVA tabel uji linieritas diperoleh nilai probabilitas sig. 0,378 dan juga nilai $\mathrm{F}$ sebesar 1,24. Jika dibandingkan dengan nilai alpha yaitu 0,05 maka nilai probabilitas sig. lebih besar $(0,378>0,05)$. Jika menggunakan nilai $\mathrm{F}$ maka $\mathrm{F}_{\text {hitung }}=1,24<$ dari $\mathrm{F}_{\text {tabel }(1,10)}=$
4,96 sehingga dari hasil tersebut dapat disimpulkan bahwa hubungan antara $\mathrm{X}$ dengan $\mathrm{Y}$ adalah linier.

Tabel 3. Uji Regresi dan Signifikansi Data (X) pada (Y)

\begin{tabular}{|c|c|c|c|c|}
\hline \multirow{2}{*}{\multicolumn{3}{|c|}{$\begin{array}{lll}\text { Variabel } & R & R^{2}\end{array}$}} & \multicolumn{2}{|c|}{$\begin{array}{l}\text { Koefisien Uji } \\
\text { Determin Signifika }\end{array}$} \\
\hline & & & asi & nsi \\
\hline $\begin{array}{c}\mathrm{X} \\
\text { terhadap }\end{array}$ & 0,083 & 0,00 & $0,07 \%$ & $\begin{array}{l}\mathrm{t}-\text { hitung }= \\
(-0,361)\end{array}$ \\
\hline $\mathbf{Y}$ & & & & $\begin{array}{l}\mathrm{t}-\text { tabel }= \\
(1,73)\end{array}$ \\
\hline
\end{tabular}

Untuk mengetahui besarnya korelasi antara motivasi latihan (X) terhadap prestasi bulutangkis (Y) menggunakan tabel model summary yang mana besarnya nilai korelasi/ hubungan (R) yaitu sebesar 0,083. Dengan demikian dapat disimpulkan bahwa hubungan antara motivasi latihan terhadap prestasi bulutangkis adalah sangat rendah dan bersifat positif. Untuk melihat besaran hubungan tersebut dari nilai $\mathrm{R}^{2}$ yaitu sebesar 0,007 sehingga besarnya determinsi motivasi latihan (X) terhadap prestasi bulutangkis adalah sebesar 0,07\% sedangkan 99,3\% dipengaruhi oleh variabel yanglain.

Pada output spss dalam tabel anava menjelaskan tidak terdapat pengaruh yang signifikan dari motivasi latihan terhadap prestasi bulutangkis dimana dari hasil analsis regresi diperoleh nilai $\mathrm{F}=0,130$. 
Sedangkan $F_{\text {tabel }(1,20)}$ sebesar 4,38. Karena $\mathrm{F}_{\text {hitung }}<\mathrm{F}_{\text {tabel }}(0,130<4,38)$ maka dapat disimpulkan bahwa persamaan regresi antara motivasi latihan dengan prestasi bulutangkis adalah tidak berarti.

Output pada tabel coeficient menunjukkan pada kolom B yaitu baris constant adalah 4,516 sedangkan pada baris motivasi latihan adalah $-0,024$ sehingga dapat ditulis persamaan regresinya sebagai berikut : $Y=\mathbf{4 , 1 5 6}+-\mathbf{0 , 0 2 4 X}$.

Setelah mendapatkan persamaan dilanjutkan dengan uji signifikansi dari dengan uji t yaitu untuk melihat apakah terdapat pengaruh yang nyata atau signifikan dari motivasi latihan terhadap prestasi bulutangkis. Dari hasil output diketahui bahwa nilai $t=(-0,361)$. Pada taraf $\alpha=0,05$ dan $\mathrm{dk}=\mathrm{n}-1=20$, Dari daftar distribusi $t$ dengan menggunakan peluang $1-\alpha=0,95$ dengan diperoleh harga $\mathrm{t}_{(20,0,95)}=1,725$. Dalam kriteria pengujian hipotesis satu arah dinyatakan bahwa $t_{\text {Hitung }}<\mathrm{t}_{\text {Tabel }}$ pada dimana $(-0,361<$ 1,725). Maka dapat disimpulkan tidak terdapat pengaruh yang signifikan dari motivasi latihan terhadap prestasi bulutangkis.

Hasil penelitian ini membuktikan bahwa ternyata tidak ada pengaruh yang signifikan dari motivasi latihan terhadap prestasi bulutangkis pada atlet PB Indocafe Medan tahun 2020 pada saat mengikuti kejuaraan Daihatsu Astec Open Tahun 2020 di Sumatera Utara. Dari hasil penelitian terdapat korelasi antar variabel sebesar $0,07 \%$ dimana korelasi itu termasuk dalam kategori sangat rendahsedangkan 99,3\% dipengaruhi oleh variabel variabel lain.

Motivasi dalam latihan menjadi penting yang mana kegiatan yang dilakukan atlet berulang-ulang dari hari ke hari dalam waktu yang lama. Hal ini tentu akan membosankan tetapi dengan motivasi yang kuat dalam mengikuti latihan hal ini menjadi tantangan tersendiri yang harus di hadapi oleh setiap atlet sehingga bisa berprestasi (Clarasasti, E. I., \& Jatmika, D., 2017).

Motivasi atlet bulutangkis PB Indocafe perlu untuk ditingkatkan bagi yang memiliki motivasi rendah dan bagi yang memiliki motivasi tinggi perlu untuk dipertahankan. Hal ini disebabkan karena motivasi menjadi faktor utama yang harus dimiliki oleh seorang atlet untuk tetap konsisten dalam latihan, mau mengembangkan diri sendiri dan memiliki kemauan yang kuat untuk melakukan evaluasi terhadap cara bermain yang dilakukannya (Kuspriyani, D. S., 2014). 
Motivasi harus selalu dibina baik oleh pelatih, orang tua atlet maupun atlet itusendiri.

Terdapat banyak hal atau variabel lain selain motivasi dari latihan yang mempengaruhi prestasi bulutangkis seperti kemampuan teknik, taktik, fisik dan juga mental bertanding (Pratama, R. R., 2019). Dimana motivasi latihan adalah salah satu komponen dari pengembangan mental padasaat bertanding.

Dengan latihan yang keras yang mana pelatih memberikan program secara sistematis terhadap perkembangan atletnya maka akan membina kemampuan atlet tersebut dimana pada saat bertanding hal tersebut sangat dibutuhkan untuk memenangkan setiap pertandingan yang diikutinya (Putra, G. I. (2018).

\section{KESIMPULAN}

Hasil penelitian ini membuktikan bahwa ternyata tidak ada pengaruh yang signifikan dari motivasi latihan terhadap prestasi bulutangkis pada atlet PB Indocafe Medan tahun 2020 pada saat mengikuti kejuaraan Daihatsu Astec Open Tahun 2020 di Sumatera Utara. Walaupun hasil penelitian menujukkan bahwa motivasi latihan tidak memberikan pengaruh yang signifikan terhadap prestasi bulutangkis tetapi dari pendapat para atlet yang diberikan isian pada saat penelitian mengatakan bahwa motivasi latihan sangat penting dalam pencapaian prestasi bulutangkis karena latihan merupakan langkah awal untuk memembentuk kemampuan sehingga dapat bersaing dan menujukkan kemampuan terbaik pada saat mengikuti pertandingan.

\section{DAFTAR PUSTAKA}

Arifin, A. Z., Januarto, O. B., \& Tomi, A. (2020). Upaya meningkatkan pukulan forehand dropshot bulutangkis menggunakan metode variasi untuk atlet usia 8-12 tahun. Sport Science and Health, 2(6), 312-322.

Clarasasti, E. I., \& Jatmika, D. (2017). Pengaruh Kecemasan Berolahraga terhadap Motivasi Berprestasi Atlet Bulutangkis Remaja di Klub J Jakarta. Humanitas

(Jurnal Psikologi), 1(2), 121-132.

Juariyah, L., \& Adi, S. S. (2017). Dampak Motivasi Dan Kepuasan Terhadap Prestasi: Pengujian Teori Motivasi Determinasi Diri (Self Determination Theory). Ekonomi Bisnis, 22(2), 143-150.

Kuspriyani, D. S. (2014). Survei Motivasi Prestasi Atlet Klub Bulutungkis Pendowo Semarang Tahun 2014. Journal of Physical Education Health and Sport, 1(2), 108-114.

Pratama, R. R. (2019). Pengaruh Gizi, Motivasi dan Percaya Diri Terhadap 
Prestasi Atlet Sepakbola Universitas

Sriwijaya. Journal Of Sport

Education (JOPE), 1(2), 37-42.

Purnamaningsih, I. R. (2019). Pengaruh

Manajemen Kepelatihan dan

Motivasi Berprestasi Terhadap

Prestasi Atlet Bola Voli Club Silvas

Kecamatan Cijulang Kabupaten

Pangandaran. Jurnal Speed (Sport, Physical Education, Empowerment), 2(1), 43-53.

Putra, G. I. (2018). Analisis Peran Pelatih Terhadap Prestasi Bulutangkis Di Kabupaten Bungo. Jurnal Muara Olahraga, 1(1), 1-13.

Rasyid, M. L. S. A., \& Kusnanik, N. W. (2021). Motivasi Berlatih Atlet Bulutangkis Selama Pandemi Covid19. Jurnal Prestasi Olahraga, 4(4), 128-138.

Sepriadi, S. (2017). Pengaruh Motivasi Berolahraga Dan Status Gizi Terhadap Tingkat Kebugaran Jasmani. Jurnal Penjakora, 4(1), 7789.

Sugiyono. (2007). Metode Penelitian Kuantitatif Kualitatif dan R\&D. Bandung: Alfabeta 